ISSN 0103-9954

\title{
EFEITO DA VAPORIZAÇÃO DE TORAS NA REDUÇÃO DOS DEFEITOS ASSOCIADOS A TENSÕES DE CRESCIMENTO DE Eucalyptus grandis
}

\author{
EFFECT OF LOG STEAMING ON THE REDUCTION OF DEFECTS ASSOCIATED WITH GROWTH \\ STRESS OF Eucalyptus grandis
}

\author{
Fred Willians Calonego $^{1}$ Elias Taylor Durgante Severo ${ }^{2}$
}

\begin{abstract}
RESUMO
O presente estudo teve como objetivo avaliar o efeito da vaporização de toras na redução de defeitos associados com as tensões de crescimento residuais em Eucalyptus grandis. Para, tanto foram utilizadas toras com diâmetros de 20 a $<25 \mathrm{~cm}$, de 25 a $<30 \mathrm{~cm}$ e de 30 a $<35 \mathrm{~cm}$, procedentes do Horto Florestal de Mandurí, SP. Metade do número de toras foi vaporizada a $90^{\circ} \mathrm{C}$ de temperatura e $100 \%$ de umidade relativa durante 20 horas. Posteriormente, as toras foram desdobradas pelo sistema de corte tangencial e realizadas medições dos defeitos decorrentes das tensões de crescimento em toras de diferentes classes de diâmetro. Os resultados evidenciam que: a vaporização das toras proporcionou a liberação de grande parte das tensões de crescimento, sem contudo eliminá-las por completo, mostrando que esse tratamento é tecnicamente viável e recomendável para a liberação das tensões de crescimento; as tábuas provenientes de toras vaporizadas de 20 a $<25 \mathrm{~cm}$ de diâmetro apresentaram, em geral, maiores reduções nos índices de defeitos, mostrando que quanto menor foi o diâmetro das toras maior foi a eficiência do tratamento de aplicação de vapor a $90^{\circ} \mathrm{C}$ de temperatura durante 20 horas.
\end{abstract}

Palavras-chave: Eucalyptus grandis; tensões de crescimento, vaporização de toras, desdobro da madeira.

\begin{abstract}
The present study was carried out to evaluate log steaming effect on the reduction of defects associated with residual growth stress of Eucalyptus grandis wood. There were used logs with diameter of 20 to $<25,25$ to $<30$ and 30 to $<35 \mathrm{~cm}$, from the Horto Florestal, Manduri, São Paulo. Half of the $\operatorname{logs}$ was steamed during 20 hours at $90^{\circ} \mathrm{C}$ of temperature and $100 \%$ of relative humidity. Subsequently, the logs were live sawn and the defects resulting from the growth stresses in logs of various diameter were measured. The results indicate that $\log$ steaming provided the release of a great part of the growth stresses, without eliminating them completely, showing, nevertheless, that this treatment is feasible and advisable for growth stress relief; the boards coming from heated logs of 20 to $<25 \mathrm{~cm}$ presented, in general, larger defect reduction, showing that the smaller the log diameter the higher the efficiency of steam treatment at $90^{\circ} \mathrm{C}$ of temperature during 20 hours.
\end{abstract}

Key words: Eucalyptus grandis; growth stresses; log steaming; sawing process.

\section{INTRODUÇÃO}

O Eucalyptus é um gênero exótico de rápido crescimento e tem sido largamente utilizado em substituição às madeiras nativas. Uma vez que a madeira de eucalipto se apresenta como uma solução para a indústria de serrados, estudar esse material é imprescindível para a produção de peças com qualidade. O seu emprego, entretanto, tem causado problemas durante o processamento da madeira por causa do aparecimento de defeitos que conduzem à consideráveis perdas de matéria-prima e, conseqüentemente, perdas econômicas.

Dentre os principais problemas decorrentes da utilização do gênero Eucalyptus, destacam-se os altos níveis de tensões de crescimento, forças encontradas na madeira em estado verde e que se manifestam na tora por meio de rachaduras, no momento ou logo após a derrubada e também durante o desdobro do material.

Uma forma comercialmente atrativa de se melhorar a qualidade do desdobro e minimizar as perdas de matéria-prima é o emprego do tratamento térmico, em toras, cuja técnica consiste em aplicar vapor ou

1. Engenheiro Florestal, Pós-Graduando em Agronomia - Energia na Agricultura pela Universidade Estadual Paulista, Fazenda Experimental Lageado, CEP 18603-970, Botucatu (SP). fwcalonego@ig.com.br

2. Engenheiro Florestal, Dr., Professor do Departamento de Recursos Naturais, Universidade Estadual Paulista, Fazenda Experimental Lageado, CEP 18603-970, Botucatu (SP). severo@fca.unesp.br

Recebido para publicação em 20/10/2004 e aceito em 27/10/2005. 
água quente por determinado tempo com o intuito de fornecer calor para as toras, plasticizar o material e concomitantemente promover o alívio das tensões de crescimento.

Por causa da produção de Eucalyptus grandis, suas propriedades mecânicas favoráveis ao uso estrutural e suas limitações físicas contornáveis pelo uso de técnicas de alívio das tensões de crescimento, verifica-se a necessidade do desenvolvimento da técnica de vaporização de toras para melhorar a qualidade da madeira, e conseqüentemente, agregar valor ao produto.

O presente trabalho teve por objetivo avaliar o efeito da vaporização de toras na redução de defeitos associados com as tensões de crescimento residuais em Eucalyptus grandis.

\section{REVISÃO BIBLIOGRÁFICA}

\section{Tensões de crescimento: origem e conseqüências}

As tensões de crescimento são responsáveis por grande proporção de defeitos que ocorrem com a madeira de eucalipto durante todas as fases de processamento. Tais defeitos implicam em grande perda do rendimento e, conseqüentemente, no desestímulo do uso do eucalipto como madeira serrada.

Wilkins (1986), comenta que enquanto os pesquisadores mais antigos atribuíam a origem das tensões de crescimento ao peso da árvore, à tensão do alburno e ao encurtamento longitudinal das células, somente essa última hipótese tem sido geralmente aceita nos dias atuais.

Para Boyd (1972), Chafe (1979) e Sales (1986), a origem das tensões de crescimento está diretamente relacionada com a lignificação das paredes celulares. Segundo os mesmos autores, a lignina depositada e polimerizada entre as microfibrilas na parede secundária induz a um irreversível inchamento ou expansão no plano transversal da célula.

Segundo Boyd (1972) e Sales (1986), essa importante deformação, no sentido transversal da fibra, provoca aumento ou diminuição do comprimento da célula, em razão do ângulo microfibrilar da camada S2 da parede secundária.

Como na parede secundária, os ângulos microfibrilares são geralmente pequenos, ocorre o encurtamento das células (Boyd, 1972; Chafe, 1979 e Sales, 1986). Os mesmos autores afirmam que a maior rigidez das fibras vizinhas, diferenciadas e ligadas, restringe a extensão do decréscimo em comprimento das células novas, de modo que se desenvolve um estresse longitudinal de tração.

Para Boyd (1972) e Sales (1986), o estresse longitudinal de tração sendo continuamente gerado pelas sucessivas camadas de células novas comprime toda a madeira mais velha. Os efeitos das novas camadas acumulam-se e as deformações mudam progressivamente a cada distância partindo da periferia, levando o centro a um estado de compressão crescente.

Segundo Nicholson (1973), o gênero Eucalyptus é um exemplo de madeira comercial em que a componente longitudinal das tensões de crescimento gerada pela formação das células novas do xilema pode apresentar valores excessivamente altos. Os altos níveis de tensões de crescimento causam rachaduras das toras, distorção das pranchas retiradas das toras e rachaduras internas.

\section{Alívio das tensões de crescimento: anelamento e vaporização de toras Anelamento das toras}

O anelamento consiste em efetuar um corte com motosserra em torno do tronco, antes da derrubada e na posterior confecção dos toretes.

A eficiência do anelamento com motosserra aumenta com o aumento de sua profundidade. A distância entre o anelamento e o topo da tora é menor quanto mais profundo for o anelamento. De forma geral, a profundidade do corte varia de $1 / 3$ a $1 / 2$ do raio (Kubler, 1987).

Sales (1986) concluiu que o nível 0 (zero) de tensões se localiza a uma distância média de $70 \%$ do raio da tora, partindo da medula. O mesmo autor afirma que o nível de estresse médio é reduzido depois da remoção da parte externa da tora, na profundidade de, aproximadamente, 1/3 do raio.

Rozas Mellado (1993), estudando Eucalyptus grandis, recomenda a realização do tratamento de 
anelamento com motosserra a uma profundidade de, aproximadamente, $1 / 3$ do raio da tora por ter um efeito positivo sobre a liberação das tensões de crescimento. Segundo o mesmo autor, o anelamento de toras evita a formação de rachadura de topo durante a confecção dos toretes e reduz sensivelmente a propagação de rachaduras nos topos das toras durante o aquecimento (vaporização).

\section{Processo de aquecimento ou vaporização de toras}

$\mathrm{O}$ aquecimento de toras, em água ou em vapor, tem como objetivo amolecer a madeira e liberar as tensões de crescimento (USDA, 1999).

O tempo necessário de permanência da tora no tanque de aquecimento depende de vários fatores, tais como: espécie, diâmetro, teor e gradiente de umidade, temperatura inicial, temperatura desejada, tipo de tanque de aquecimento e meio utilizado como aquecedor (Steinhagen et al., 1980 e Umaña e Brito, 2003).

Segundo Mackay (1971), Simpson (1975) e Weik et al. (1984), a vaporização da madeira é uma técnica que tem sido explorada para uma grande variedade de propósitos. Estes incluem a redução dos níveis de tensões de crescimento, aumento da permeabilidade e melhoria na estabilidade dimensional.

Tejada et al. (1997), estudando o efeito da vaporização de toras na liberação das tensões de crescimento em Cryptomeria japonica D. Don, verificaram que o tratamento de aplicação de vapor a altas temperaturas durante 70 horas tem um efeito positivo no relaxamento das tensões da madeira. Os mesmos autores afirmam que esse processo é efetivo para reduzir até cerca de $100 \%$ das tensões de crescimento.

Rozas Mellado (1993), estudando Eucalyptus grandis, confirmou que o tratamento de vaporização de toras previamente aneladas foi efetivo na liberação das tensões de crescimento. Para isso, o referido autor recomendou o uso de um tempo de vaporização de 18 horas e uma temperatura de $90^{\circ} \mathrm{C}$ para toras com diâmetro entre 15 e $20 \mathrm{~cm}$. O mesmo autor concluiu que a utilização do tratamento de vaporização melhorou a qualidade da madeira serrada, uma vez que esse tratamento provocou uma diminuição das rachaduras e empenamentos durante o desdobro de E. grandis.

Skolmen (1967), obteve reduções de cerca de 50\% das tensões de crescimento em toras de Eucalyptus saligna com diâmetro de $15-20 \mathrm{~cm}$ após um tratamento de 24 horas em água quente. Em estudo semelhante, Severo e Tomaselli (2000) concluíram que a vaporização de toras de Eucalyptus dunni, a $100^{\circ} \mathrm{C}$ de temperatura durante 20 horas, proporcionou uma redução significativa nas tensões de crescimento na ordem de 50\% do comprimento e largura das rachaduras e da abertura das tábuas em relação às toras.

\section{Sistema de corte e desdobro da madeira}

O aprimoramento de técnicas de desdobro, aliado ao uso adequado de técnicas de secagem da madeira, é de fundamental importância para a obtenção de um melhor rendimento das espécies de rápido crescimento e que possuem acentuados níveis de tensões de crescimento.

Segundo Garcia (1995), o desdobro da madeira de eucalipto exige técnicas especiais por causa das condições intrínsecas da madeira. A grande ocorrência de tensões internas de crescimento prejudica sobremaneira o rendimento, pela tendência de rachamento das toras antes e durante a operação de desdobro.

Segundo Acosta (1999), toras de Eucalyptus grandis, com diâmetro médio entre 25 e $30 \mathrm{~cm}$ e comprimento máximo de 3,5 a $4,5 \mathrm{~m}$, devem receber o primeiro corte em uma serra de fita dupla para a retirada de duas costaneiras simultaneamente. Tal sistema de corte promove a liberação por igual das tensões de crescimento. Após, então, o bloco central, com no mínimo $67 \%$ do diâmetro da tora, passa por serras de fita ou circulares múltiplas.

Garcia (1995) salienta que, no caso da peça que pode ser obtida por um corte duplo seguido de um corte múltiplo, se observa que o encanoamento diminui e a flecha do encurvamento tende a aumentar com o aumento da distância da peça em relação à medula.

O mesmo autor afirma que tal peça, em razão da sua menor inércia, pode ser retificada na secagem mediante a aplicação de cargas transversais, mas, nesse caso, guardará tensões residuais que poderão manifestar-se por ocasião de cortes longitudinais posteriores. Recomenda, então, que suas dimensões sejam as mais próximas possíveis daquelas necessárias ao seu uso final. 
Montagna et al. (1991), estudando o efeito das tensões de crescimento da madeira de Eucalyptus grandis, de 18 anos de idade e com DAP de $23 \mathrm{~cm}$, em função do sistema de desdobro, verificaram que a espécie, quando desdobrada por uma serra de fita simples pelo sistema de corte tradicional (cortes paralelos), produziu tábuas com o valor do índice de rachaduras nove vezes maior quando comparado ao das tábuas obtidas pelo desdobro de toras no sistema de cortes realizado mediante o uso de uma serra de fita geminada para obtenção do bloco por meio da retirada das costaneiras, duas a duas.

\section{MATERIAL E MÉTODO}

\section{Coleta do material}

Foram estudadas árvores de Eucalyptus grandis Hill ex Maiden com 30 anos de idade. O material foi proveniente da Floresta Estadual de Santa Bárbara, pertencente ao Instituto Florestal - Seção de Manduri, localizada em Águas de Santa Bárbara cujo plantio foi realizado em 1973.

A área em estudo, com 2,2 hectares, possuía espaçamento inicial de 2,0 m x 3,0 m e passou por três desbastes seletivos antes da coleta do material.

A coleta do material envolveu o abate, ao acaso, de 14 árvores de Eucalyptus grandis. A operação de abate foi realizada com motosserras e as árvores foram cortadas o mais próximo do solo. O fuste, de cada uma das 14 árvores, foi traçado de forma que permitiu a retirada de toras com $2,9 \mathrm{~m}$ de comprimento, as quais foram agrupadas em três classes de diâmetro: $20 \mathrm{a}<25 \mathrm{~cm}, 25 \mathrm{a}<30 \mathrm{~cm}$ e $30 \mathrm{a}<35 \mathrm{~cm}$.

\section{Tratamentos para alívio das tensões de crescimento}

Para aliviar as tensões de crescimento os tratamentos, constituíram-se em anelamento de todas as toras, realizados no campo, e em vaporização de parte das toras das três classes de diâmetros envolvidas no estudo, no Laboratório de Secagem e Preservação de Madeiras da FCA/UNESP de Botucatu-SP.

\section{Anelamento das toras}

As toras de 2,9 m de comprimento foram aneladas a $10 \mathrm{~cm}$ de cada uma das extremidades numa profundidade aproximada de $1 / 3$ do raio da tora, conforme proposto por Kubler (1987), Rozas Mellado (1993) e Sales (1986). Esse procedimento pode ser observado no esquema simplificado da Figura 1.

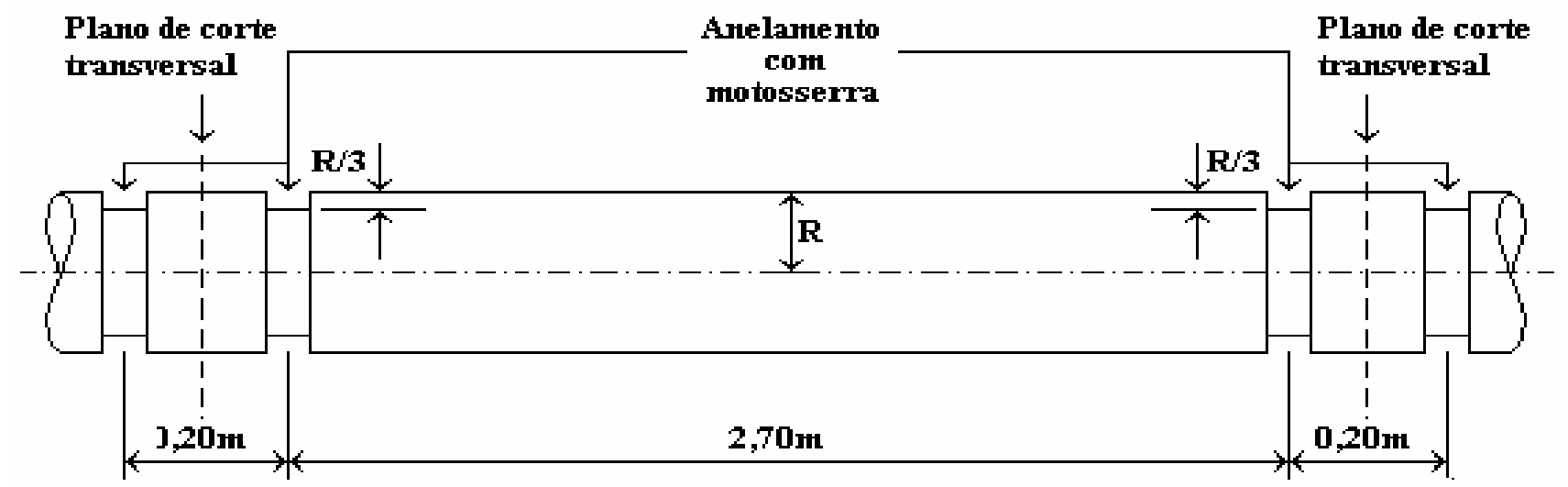

FIGURA 1: Esquema de anelamento das toras com motosserra.

FIGURE 1: Scheme of aneling of logs with chain-saw.

\section{Vaporização de toras}

O meio vaporizador, neste estudo, foi uma estufa de secagem convencional do Laboratório de Secagem e Preservação de Madeiras - FCA/UNESP que, por causa da presença de uma caldeira capaz de gerar vapor com $8 \mathrm{kgf} / \mathrm{cm}^{2}$ de pressão, teve a mesma finalidade de um tanque vaporizador de toras. As toras foram vaporizadas a $90^{\circ} \mathrm{C}$ de temperatura e $100 \%$ de umidade relativa por 20 horas. 


\section{Desdobro das toras}

Todas as toras (controle e vaporizadas) foram desdobradas em tábuas tangenciais conforme sistema de corte apresentado na Figura 2. O sistema de corte utilizado para a obtenção das tábuas tangenciais é o mesmo utilizado por Montagna et al. (1991) e proposto por Acosta (1999) para o gênero Eucalyptus.

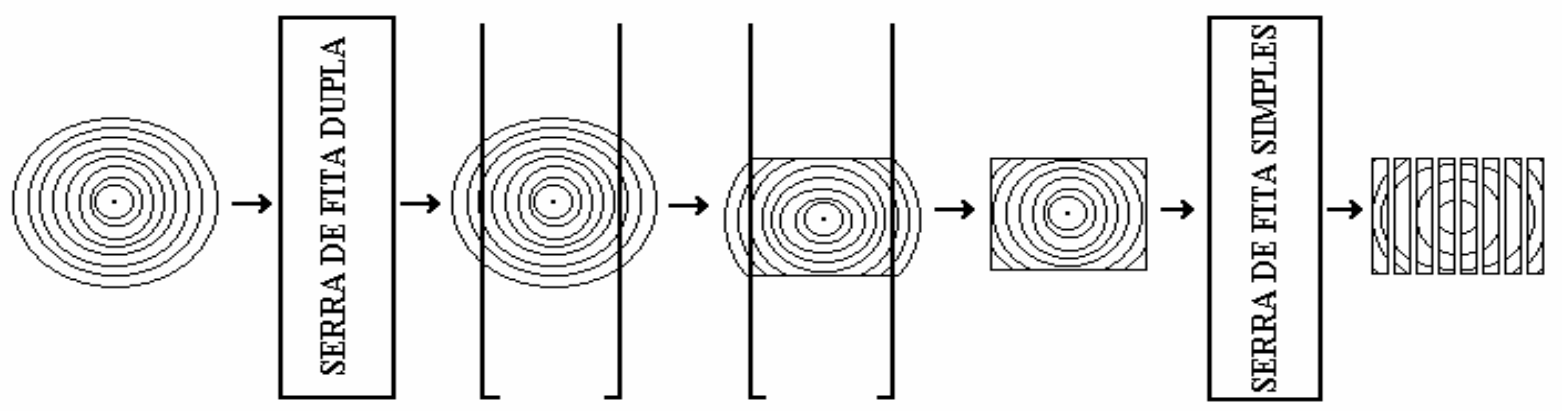

FIGURA 2: Método de desdobro visando à obtenção de peças tangenciais baseado em serras de fita geminada e simples.

FIGURE 2: Method of sawing process using twin and simple band saw.

A serraria está localizada no Horto Florestal de Mandurí, e para a confecção de blocos, foi utilizada uma serra de fita dupla com as seguintes características: diâmetro dos volantes: $1,10 \mathrm{~m}$; largura dos volantes: $11,5 \mathrm{~cm}$; dimensão da polia do motor: $27 \mathrm{~cm}$; dimensão da polia do volante: $38 \mathrm{~cm}$; rotação do motor: 1170 rpm; potência do motor: $22 \mathrm{Kw}=29,9 \mathrm{Hp}$; altura máxima de corte da serra: $35,36 \mathrm{~cm}$; espessura da lâmina de serra: $1,3 \mathrm{~mm}$ e espessura de corte da serra: $3,2 \mathrm{~mm}$.

As tábuas com $28 \mathrm{~mm}$ de espessura foram confeccionadas com uma re-serra de fita com as seguintes características: diâmetro dos volantes: $1,10 \mathrm{~m}$; largura dos volantes: $11,5 \mathrm{~cm}$; dimensão da polia do motor: 27 $\mathrm{cm}$; dimensão da polia do volante: $38 \mathrm{~cm}$; rotação do motor: $1175 \mathrm{rpm}$; potência do motor: $18,5 \mathrm{Kw}=25,15$ Hp; espessura da lâmina de serra: $1,2 \mathrm{~mm}$ e espessura de corte da serra: $3,2 \mathrm{~mm}$.

Como as toras desdobradas estavam agrupadas nas classes de diâmetro de $20 \mathrm{a}<25 \mathrm{~cm}$, de $25 \mathrm{a}<30$ $\mathrm{cm}$ e de 30 a $<35 \mathrm{~cm}$, obtiveram-se tábuas com larguras de $14,0 \mathrm{~cm}$, de $17,5 \mathrm{~cm}$ e de $21,0 \mathrm{~cm}$ respectivamente definidas de acordo com as dimensões dos blocos, conforme esquema na Figura 3. 

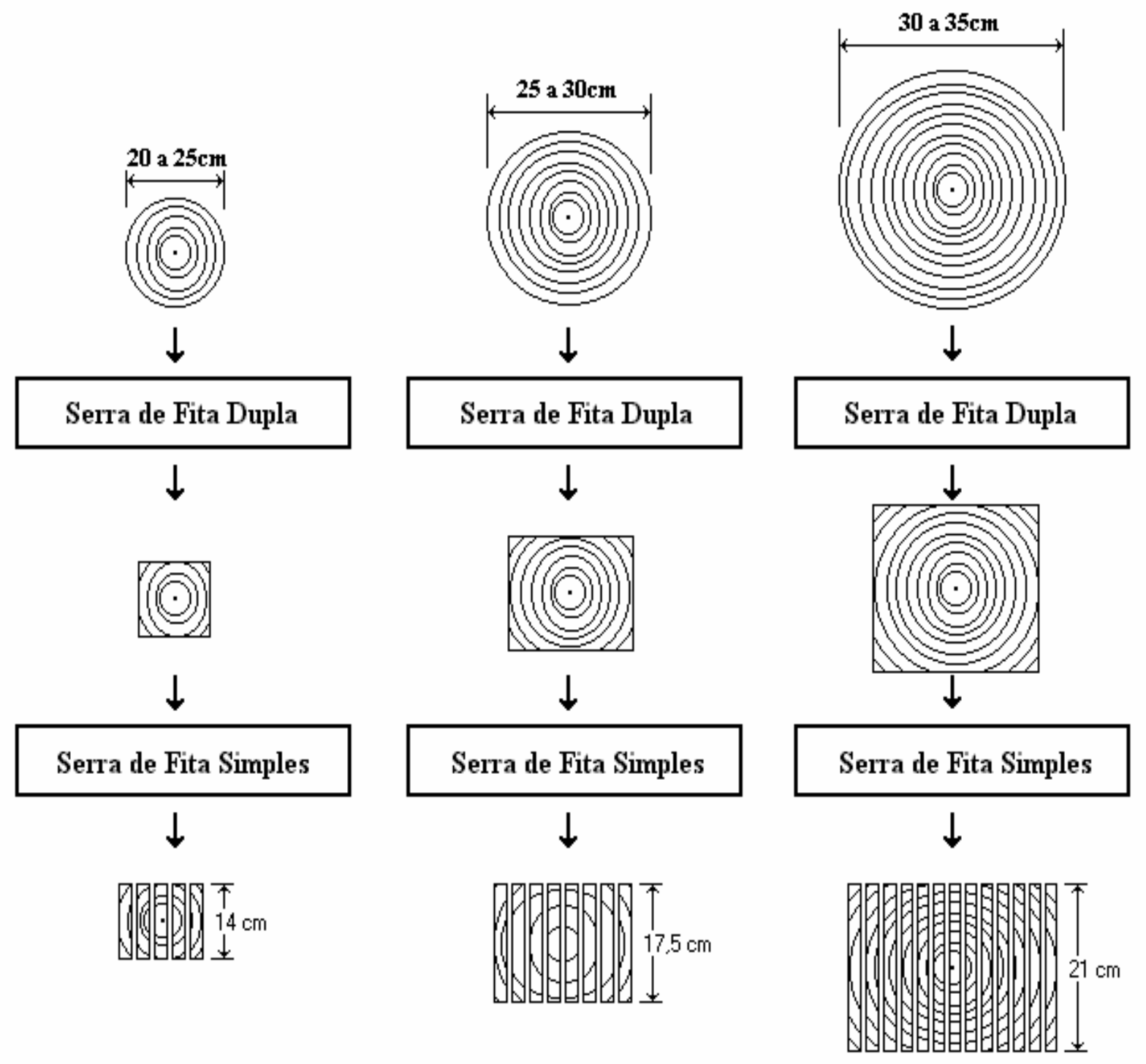

FIGURA 3: Esquema da obtenção de peças com larguras definidas pelo diâmetro das toras.

FIGURE 3: Scheme of obtaining boards with width defined by log diameter.

Com a adoção desse critério, puderam-se otimizar o desdobro e a obtenção de madeira serrada e avaliar o efeito da vaporização das toras na qualidade dos serrados.

\section{Avaliação das tensões de crescimento}

Para avaliação indireta das tensões de crescimento residuais, foram medidas as aberturas das tábuas em relação ao bloco (linha de corte) no momento do desdobro, os empenamentos e as rachaduras.

Para avaliação das rachaduras, foram medidos o comprimento e a largura de todas as rachaduras de topo presentes nas tábuas, tanto na entrada como na saída da serra (dois extremos das tábuas). $\mathrm{O}$ esquema dessas medições pode ser verificado na Figura 4. 


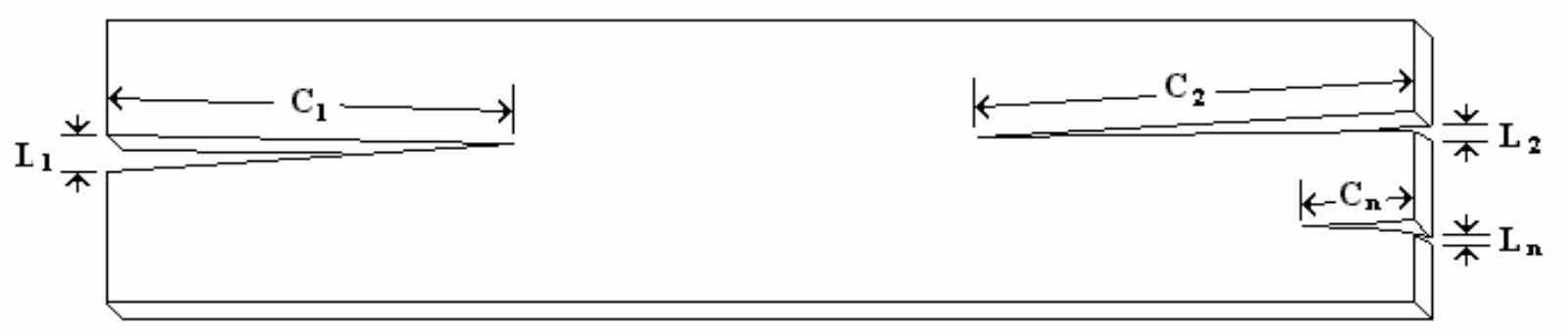

\section{$\mathrm{C}$ - comprimento das rachaduras, $\mathrm{cm}$; \\ $\mathrm{L}$ - largura das rachaduras, mm.}

FIGURA 4: Esquema de medição de rachadura de uma tábua após o desdobro.

FIGURE 4: Scheme of measurement of board after the sawing process.

A abertura da tábua em relação ao bloco foi tomada quando a serra fita simples encontrava-se à cerca de 2,0 metros do comprimento final da tábua. A medição desse defeito pode ser visualizada na Figura 5.

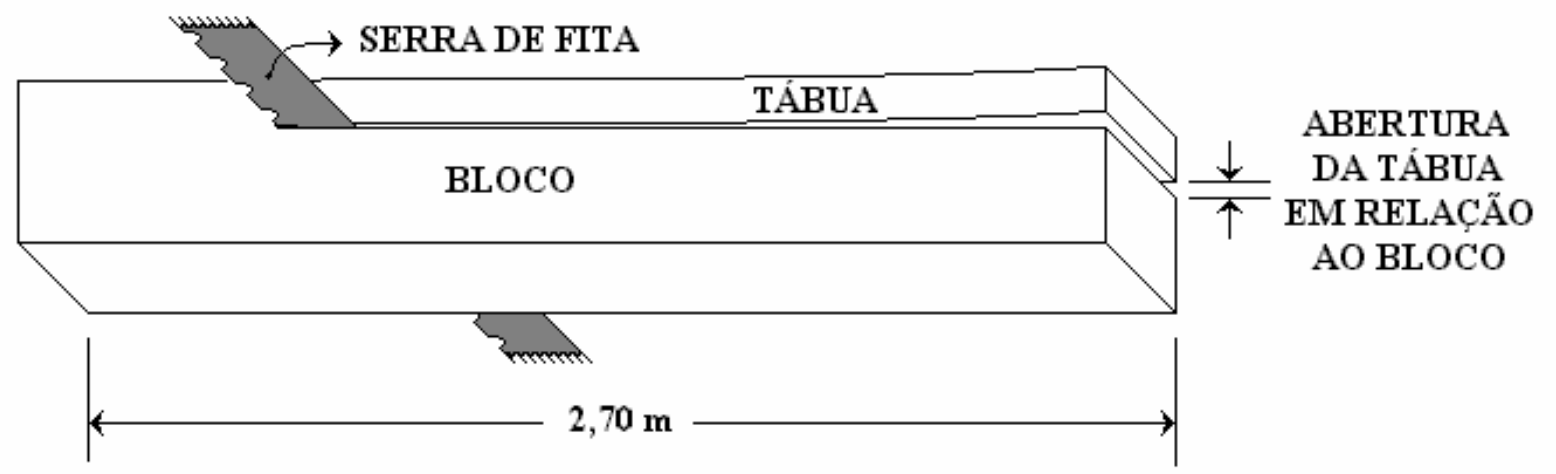

FIGURA 5: Esquema de medição da abertura da tábua em relação ao bloco no desdobro.

FIGURE 5: Scheme of measurement of the gap of the board in relation to the block in the sawing process.

Foi utilizado o delineamento experimental inteiramente ao acaso com os tratamentos no esquema fatorial, levando-se em consideração o tratamento de vaporização. A análise exploratória dos dados das variáveis abertura das tábuas em relação ao bloco, do comprimento e da largura das rachaduras produzidas na tábuas, durante o desdobro, recomendou a adoção de métodos de análise não-paramétrica (KruskallWallis) para análise de variância. O grande número de tábuas com índice nulo dos defeitos estudados foi responsável pela distribuição não-normal dos dados como mostraram os testes de normalidade (ShapiroWilk, Kolmogorov-Smirnov, Cramer-von Mises e Anderson-Darling), os histogramas e os gráficos de probabilidade normal.

\section{RESULTADOS E DISCUSSÃO}

A avaliação indireta das tensões de crescimento residuais levou em consideração a forma como essas tensões se manifestam na madeira serrada, pelas medições de empenamentos, rachaduras e abertura das tábuas em relação ao bloco.

É fato que a abertura das tábuas em relação ao bloco é a variável de resposta para o desbitolamento das tábuas. Porém, a avaliação da variação em espessura das tábuas não foi realizada em razão da ausência de um carro-porta-toras na serra de fita simples. O avanço do bloco na serra ocorreu pelo auxílio de dois operários e, conseqüentemente, houve interferência na variação da espessura das peças.

A avaliação das tábuas durante o desdobro indicou que não houve nenhum tipo de empenamento, tanto em tábuas provenientes de toras controle (aneladas) como de toras vaporizadas (aneladas e vaporizadas). Situação semelhante foi relatada por Severo e Tomaselli (2000) ao verificarem a ausência de 
empenamentos na madeira serrada logo após o desdobro de toras controle e vaporizadas de Eucalyptus dunni.

O mesmo fato não ocorreu para as variáveis rachaduras e abertura das tábuas em relação ao bloco. Os resultados dessa avaliação se encontram na Tabela 1. Os testes de Kruskal-Wallis mostram que a vaporização das toras proporcionou considerável redução em todas as variáveis utilizadas como parâmetros de comparação do nível das tensões de crescimento durante o desdobro de toras de Eucalyptus grandis com $20 \mathrm{a}<25,25 \mathrm{a}<30$ e 30 a $<35 \mathrm{~cm}$ de diâmetro.

TABELA 1: Efeito da vaporização de toras no alívio das tensões de crescimento.

TABLE 1: Effect of log steaming in the growth stresses relief.

\begin{tabular}{|c|c|c|c|c|}
\hline \multirow[t]{2}{*}{ Diâmetro das Toras } & \multirow[t]{2}{*}{ Tratamentos } & \multirow{2}{*}{$\begin{array}{c}\text { Abertura } \\
(\mathrm{mm})\end{array}$} & \multicolumn{2}{|c|}{ Rachaduras de Topo } \\
\hline & & & Comprimento $(\mathrm{cm})$ & Largura $(\mathrm{mm})$ \\
\hline \multirow[t]{2}{*}{$30-35 \mathrm{~cm}$} & Controle & 20,9 & $106,3^{*}$ & $20,5^{*}$ \\
\hline & Vaporizada & 19,6 & $69,4^{*}$ & $10,8^{*}$ \\
\hline Redução (\%) & & $6,2^{\mathrm{NS}}$ & $34,7^{*}$ & $47,3 *$ \\
\hline \multirow[t]{2}{*}{$25-30 \mathrm{~cm}$} & Controle & $24,8^{*}$ & $82,0^{*}$ & $15,8^{*}$ \\
\hline & Vaporizada & $19,7^{*}$ & $53,5^{*}$ & $7,9 *$ \\
\hline Redução (\%) & & $20,6^{*}$ & $34,8^{*}$ & $50,0^{*}$ \\
\hline \multirow[t]{2}{*}{$20-25 \mathrm{~cm}$} & Controle & $31,8^{*}$ & $54,3^{*}$ & $10,0^{*}$ \\
\hline & Vaporizada & $21,5^{*}$ & $35,8^{*}$ & $5,3^{*}$ \\
\hline Redução (\%) & & $32,4^{*}$ & $34,1^{*}$ & $47,0^{*}$ \\
\hline \multirow[t]{2}{*}{ Todas as classes } & Controle & $24,9^{*}$ & $85,2^{*}$ & $16,3^{*}$ \\
\hline & Vaporizada & $20,2^{*}$ & $54,5^{*}$ & $8,2^{*}$ \\
\hline Redução (\%) & & $18,9^{*}$ & $36,4^{*}$ & $49,7 *$ \\
\hline
\end{tabular}

Em que: NS = não-significativo; * = significativo ao nível de $95 \%$ de probabilidade.

Considerando tábuas provenientes de todas as classes de diâmetros em estudo agrupadas em uma só classe, se verificam reduções da abertura das tábuas em relação ao bloco, comprimento e largura das rachaduras com a vaporização na ordem de 18,9,36,4 e 49,7\%, respectivamente.

Verifica-se, na Tabela 1, que as reduções da abertura das tábuas, em relação ao bloco por causa da vaporização se apresentam na ordem de 6,2\% (não-significativa), 20,6 e 32,4\% (significativas) para toras de 30 a $<35,25$ a $<30$ e 20 a $<25 \mathrm{~cm}$ respectivamente. Isso mostra que, embora a vaporização tenha sido mais eficiente na redução da abertura das tábuas em relação ao bloco em toras de $20 \mathrm{a}<25 \mathrm{~cm}$ de diâmetro, se verifica que o nível do defeito em questão, no material vaporizado, foi semelhante para as três classes de diâmetro $(19,6,19,7$ e $21,5 \mathrm{~mm}$ para toras de 30 a $<35,25$ a $<30$ e 20 a $<25 \mathrm{~cm}$ de diâmetro respectivamente) e concomitantemente as toras controle de 20 a $<25 \mathrm{~cm}$ apresentaram maiores índices do defeito do que as toras de maiores diâmetros.

As reduções significativas das variáveis comprimento das rachaduras das tábuas com a vaporização foram 34,$7 ; 34,8$ e $34,1 \%$ para toras de 30 a $<35,25$ a $<30$ e 20 a $<25 \mathrm{~cm}$ de diâmetro respectivamente. Para as mesmas classes de diâmetros de toras, obtiveram-se reduções significativas da largura das rachaduras na ordem de 47,$3 ; 50,0$ e 47,0\%. Esse comportamento mostra que a vaporização da madeira por 20 horas promoveu reduções semelhantes desses defeitos para toras de diferentes classes diamétricas.

Os resultados obtidos nesse estudo são semelhantes aos obtidos por Skolmen (1967) que encontraram reduções de cerca de $50 \%$ das tensões de crescimento em toras de Eucalyptus saligna com diâmetro de 15-20 cm após um tratamento de 24 horas em água quente; e por Severo e Tomaselli (2000) que também concluíram que a vaporização das toras de Eucalyptus dunnii por um período de 20 horas 
proporcionou uma redução significativa das tensões de crescimento na ordem de $50 \%$.

Pode-se concluir que todos os defeitos decorrentes das tensões de crescimento, avaliadas neste trabalho, foram minimizados significativamente com a vaporização, em todas as classes de diâmetro, mostrando assim que o processo de vaporização de toras é uma opção tecnicamente viável para o relaxamento das tensões de crescimento.

A vaporização por 20 horas promoveu reduções semelhantes dos defeitos (comprimento e largura das rachaduras) nas tábuas provenientes de toras das três classes de diâmetro em estudo, como mostra a Tabela 1. Porém, verifica-se, pela mesma tabela, que as tábuas provenientes tanto de toras controle quanto de vaporizadas de 30 a $<35 \mathrm{~cm}$ de diâmetro apresentaram maiores índices desses defeitos quando comparadas com as de 25 a $<30 \mathrm{~cm}$. O mesmo ocorreu quando comparou-se os defeitos das tábuas de toras de 25 a $<30$ $\mathrm{cm}$ com as de menor diâmetro $(20 \mathrm{a}<25 \mathrm{~cm})$. Isso mostra que tábuas provenientes de toras vaporizadas de 20 a $<25 \mathrm{~cm}$ de diâmetro apresentam significativamente menor nível dos defeitos quando comparadas com tábuas oriundas de toras controle da mesma classe de diâmetro e também quando comparadas com tábuas provenientes de toras vaporizadas de dimensões maiores. Portanto, em conseqüência do aumento do diâmetro das toras controle, há um aumento do nível desses defeitos.

Uma das possíveis causas das tábuas de toras de maiores diâmetros apresentarem maior comprimento e largura de rachaduras também pode ser parcialmente atribuído, teoricamente, à variação da percentagem de lenhos juvenil e adulto quando se comparam toras de diferentes classes diamétricas e à presença de cerne quebradiço nas toras mais velhas e sempre associados às tábuas retiradas próximo da medula. Isso pôde ser verificado, quando realizada a medição dos defeitos. Na ocasião, constatou-se a presença acentuada das rachaduras nas tábuas que continham a medula em toras de diâmetros maiores e baixo nível desse defeito nas tábuas retiradas próximas à periferia do tronco. E nas toras menores, as dimensões das rachaduras em todas as tábuas retiradas dos blocos apresentaram valores muito próximos.

Entretanto, Steinhagen et al. (1980) e Umanã e Brito (2003) afirmam que o diâmetro das toras é de fundamental importância para a determinação do tempo de permanência do material no meio vaporizador.

O estudo realizado por Rozas Mellado (1993), com toras de Eucalyptus grandis de 15 a $20 \mathrm{~cm}$ de diâmetro, mostrou que a vaporização do material, por um período de 18 horas a uma temperatura de $90^{\circ} \mathrm{C}$, foi suficiente para eliminar as rachaduras da espécie e reduzir sobremaneira a abertura das tábuas em relação à tora. Segundo o mesmo autor, não houve diferença significativa entre o tempo de vaporização de 18 e 36 horas.

Portanto, o índice diferenciado das rachaduras, presentes nas tábuas retiradas de toras vaporizadas de 20 a $<25,25$ a $<30$ e 30 a $<35 \mathrm{~cm}$ de diâmetro de E. grandis, reforça o fato de que o diâmetro das toras é fundamental para a determinação exata do tempo de vaporização do material.

\section{CONCLUSÕES}

Pelo estudo sobre o efeito da vaporização de Eucalyptus grandis no alívio das tensões de crescimento, permitem-se as seguintes conclusões:

a) a vaporização de toras, por um período de 20 horas, aliviou as tensões de crescimento de toras de 30 a $<35,25$ a $<30$ e 20 a $<25$ cm de diâmetros;

b) toras de menor diâmetro apresentaram maior abertura das tábuas em relação ao bloco. No entanto, após a vaporização, todas as classes de diâmetros de toras apresentaram o mesmo índice do defeito;

c) embora a redução do comprimento e da largura de rachaduras de tábuas oriundas de toras vaporizadas sejam semelhantes para as três classes de diâmetros, tanto toras controle quanto vaporizadas de menor diâmetro apresentaram menor magnitude desses defeitos quando comparadas com as de maiores dimensões.

\section{REFERÊNCIAS BIBLIOGRÁFICAS}

ACOSTA, M.S. Experiência argentina en la producción y utilización de la madera de eucalipto, Panorama a 1999. In: 
WORKSHOP: TECNICAS DE ABATE, PROCESSAMENTO E UTILIZAÇÃO DA MADEIRA DE EUCALIPTO, 1999, Viçosa. Anais... Viçosa: UFV/DEF/SIF/IEF, 1999. p. 28-38.

BOYD, J.D. The growth stresses: evidence of a origin in differentiation and lignification. Wood Science and Technology, v. 6, p. 251-262, 1972.

CHAFE, S. C. Growth stresses in trees. Australian Forrest Research, v. 9, n. 3, p. 203-223, 1979.

USDA - UNITED STATES DEPARTMENT OF AGRICULTURE. Wood handbook : wood as an engineering material. Madison: U.S. Department of Agriculture, 1999. 463p.

GARCIA, J.N. Técnicas de desdobro de eucalipto. In: SEMINÁRIO INTERNACIONAL DE UTILIZAÇÃO DA MADEIRA DE EUCALIPTO PARA SERRARIA, 1995, São Paulo. Anais... Piracicaba: Instituto de Pesquisa e Estudos Florestais/ Instituto de Pesquisas Tecnológicas, 1995. p. 59-67.

KUBLER, H. Growth stresses in trees and related wood properties. Forest Products Abstracts. Farnham Royal, v. 10, n. 3, p. 61-119, 1987.

MACKAY, J.F.G. Influence of steaming on water vapor diffusion in hardwoods. Wood Science, v. 3, p. 156-160, 1971.

MONTAGNA, R.G.; PONCE, R.H.; FERNANDES, P.S.; RIBAS, C. Desdobro de Eucalyptus grandis Hill ex Maiden visando a diminuir o efeito das tensões de crescimento. Revista do Instituto Florestal, v. 3, n. 2, p. 181-190, 1991.

NICHOLSON, J.E. Growth stresses differences in eucalypts. Forest Science, v. 9, n. 3, p. 169-174, 1973.

ROZAS MELLADO, E.C.E. Contribuição ao desenvolvimento tecnológico para a utilização de madeira serrada de Eucalyptus grandis (Hill Ex Maiden) na geração de produtos com maior valor agregado. 1993. 133p. Dissertação (Mestrado em Engenharia Florestal) - Universidade Federal do Paraná, Curitiba, 1993.

SALES, C.G. Growth stresses: main results obtained on the study of guyana species and consequences for and use. In: IUFRO WORLD CONGRESS, 18, Ljubljana, 1986. Proceedings... Ljubljana: IUFRO, 1986. v. 5, p. 234-248.

SEVERO, E.T.D.; TOMASELLI, I. Efeito da vaporização no alívio das tensões de crescimento em toras de duas procedências de Eucalyptus dunnii. Sciencia Agraria, v. 1, n. 1-2, p. 29-32, 2000.

SIMPSON, W.T. Effect of steaming on the drying rate of several species of wood. Wood Science, v. 7, p. 247-255, 1975.

SKOLMEN, R. G. Heating Logs To Relieve Growth Stresses. Forest Products Journal, v. 17, p. 41-42, 1967.

STEINHAGEN, H. P; MEYERS,G.E.; KUBLER,H. Heating times charts for frozen and nonfrozen veneer logs. Forest Products Journal, v. 30, n. 4, p. 27-37, 1980.

TEJADA, A.; OKUYAMA, T.; YAMAMOTO, H.; YOSHIDA, M. Reduction of growth stress in logs by direct heat treatment: assessment of a commercial-scale operation. Forest Products Journal,, v. 47, n. 9, p. 86-93, 1997.

UMAÑA, C.L.A.; BRITO, E.O. Avaliação de tempos de cozimento de toras de três espécies florestais utilizadas na fabricação de lâminas de madeira. In: CONGRESSO INTERNACIONAL DE COMPENSADO E MADEIRA TROPICAL, 5., 2003, Pará. Anais... Pará: CDP, 2003. s.p.

WEIK, B.B.; WENGERT, E.M.; SCHOREDER, J.; BRISBIN, R.. Practical drying techniques for yellow-poplar S-D-R fliches. Forest Products Journal, v. 34, p. 39-44, 1984.

WILKINS, A.P. Nature and origin of growth stresses in trees. Australian Forestry, v. 49, n. 1, p. 56-62, 1986. 